\title{
SCHEMA INFLUENCE ON LISTENING AND SPEAKING INPUT RETENTION
}

\author{
Ernisa Marzuki' \\ Ahmed Shamsul Bahri² \\ Salina Pit ${ }^{3}$ \\ Faidz Felani Majeri ${ }^{4}$ \\ Centre for Language Studies, Universiti Malaysia Sarawak \\ 1mernisa@cls.unimas.my \\ 2mtashabri@cls.unimas.my \\ 3psalina@cls.unimas.my \\ ${ }^{4}$ mffelani@cls.unimas.my
}

\begin{abstract}
Schema has been shown to influence reading and listening processes and retention of information. At the same time, it also arguably resists new information. This study aimed to find out the level of specific item recall in participants after they were given either a listening or reading input with specific altered items. It also examined the differences in the retention of participants who possessed schema of the narrative compared with those who did not possess the schema. For the specific item recall, results revealed that regardless of the type of input, the four major altered items were recalled the most. Meanwhile, the comparison between participants with schemata and without schemata showed that those with schema performed better, with participants who listened to the input and possessing schema achieving the best retention results. The results of this study highlighted the importance of narrative selection for input in teaching and learning whilst also providing evidence that cultural schema influences the type of items recalled from both types of input.
\end{abstract}

Keywords: Listening and reading input, narrative, retention, schemata, prior knowledge, second language

\section{Introduction}

The term "schema" dates back to 1781 (Carrell, 1983) and was formally introduced by Bartlett in 1932 (Ellermeyer, 1993). It refers to the cognitive formation which plays a vital role in explaining what happens when old knowledge meets new (Brewer \& Nakamura, 1984). Chiang and Dunkel (1992) define schema as prior knowledge or world knowledge which interacts with the speech listened to, or text read, and might cause communication breakdown when there is a mismatch (Carrell \& Eisterhold, 1983). The important, overlapping elements in the schema theory 
seem to be: a) the existence of knowledge or experience from the past, known as prior/world knowledge (Chiang \& Dunkel, 1992; Markham \& Latham, 1987); old knowledge (Brewer \& Nakamura, 1984), or background knowledge (Carrell, 1983); b) this knowledge or experience is referred to when interpreting text(s) and/or context(s); and c) the person could infer or act upon the text(s) and/or context(s) as a result of the knowledge or experience. Based on these, the working definition of schema in this study is the prior knowledge from any sources which is activated, referred to and possibly followed when encountering texts. That schema is an important facet of learning is a widely accepted fact.

Over the years, schema has been studied by numerous researchers and is deemed as "a useful and powerful tool for understanding reading processes" (McVee, Dunsmore, \& Gavelek, 2005, p. 534). Research regarding schema and reading (e.g., Baldwin, Peleg-Bruckner, \& McClintock, 1985; Pritchard, 1990; Reynolds, Taylor, Steffenson, Shirey, \& Anderson, 1982) provided evidence that schema aids reading comprehension. In Baldwin et al.'s (1985) study on schema and topic interest, it was found that schema on its own was sufficient to increase reading comprehension, and that it did not correlate with the interest in the reading topic. Pritchard (1990) conducted a study on Palauan and American adolescents and found that the strategies for comprehending a text differed based on the participants' schema culture. Participants recalled more idea units from the texts which they were culturally familiar with. This was clear in the longer elaborations made by the participants when they encountered a text which was culturally familiar. As culture is ever-present in the background of any language teaching and learning context (Kramsch, 1993), one can argue that cultural schema is an important aspect of text comprehension, not only in reading, but also in listening.

Research regarding schema and second language (L2) listening comprehension, however, is scarce (Chiang \& Dunkel, 1992; Long, 1989; Sadighi \& Zare, 2006). Long (1989) mentioned that more empirical studies are needed to support schema and listening hypotheses as most research seemed to deal with reading. Chiang and Dunkel (1992) examined Chinese learners' listening comprehension during lectures. Their participants scored lower on the unfamiliar text on the Amish people compared to the more familiar text on Confucius. SchmidtReinhart (1994) conducted a similar research on Spanish university students, but added learner proficiency into the equation. She found that topic familiarity induced higher scores on the immediate recall tests, regardless of proficiency. This is similar to Baldwin et al.'s (1985) findings which showed that schema is an autonomous construct.

As mentioned before, cultural schema is an important part of text comprehension. In folktales, Propp's 31 classifications of character functions (Tomaszewski \& Binsted, 2007) are based on the cultural schema found in Russian folktales, and can be generalised to include other fairy tales from all over the world. However, Martin (2009), in her review of 25 Malaysian folktales, found that not all of Propp's classifications are satisfied by Malaysian folktales, which tend to be simpler and do not always have happy endings. The schemata of folk tales, therefore, are related to the cultural schemata of the country where they originate from. Consequently, comprehension of folktales should take cultural schema into account. 
Schema has also been shown to influence the level of retention. In a series of four experiments related to prior knowledge and brand recognition, Srull (1983) observed that participants with background knowledge of a product retained information better. They were resistant to influences that affected other participants who possessed little or no schema. In Srull's experiment, the influences came in the form of moods (e.g., happy, sad). Srull found that participants with high background knowledge of the product were not affected by their mood, but those who had low background knowledge were affected. Therefore, Srull concluded that schema provided "immunity" against "irrelevant factors" (p. 575). On the other hand, it was also found that participants who possessed the schemata were less able to discriminate the correct pairings of attributes with a product. In other words, schema may cause confusion in terms of accuracy. In a similar tone, schema may "hinder learning from text" as learners tend to disregard information which is dissimilar with their knowledge, even though schema does assist in detail recollection (Shapiro, 2004, p. 162). Therefore, the existence of schema in a learner can be a good thing as it aids in retention of information but, at the same time, can pose a problem if it influences learners to resist new information.

The retention from reading or listening to a narrative whilst taking schema into account, nevertheless, has not been attempted. The comparison between retention between reading and listening has been done for academic texts (see Vidal, 2011) but not for narratives in the form of a folktale with specifically altered items. This study presents preliminary findings regarding retention from listening and reading input during an immediate and delayed post-test on an altered local folktale. We also examined the differences in retention between participants who possessed the narrative schema and those who did not. Our research questions are as follows:

- Are there any differences in the percentage of the overall retention of altered items from the listening and reading input?

- What is the percentage of degradation of retention, if any, from the first (immediate) post-test to the second (delayed) post-test?

- How did participants with prior knowledge perform compared to participants with no prior knowledge of the narrative?

\section{Methodology}

A total of 50 undergraduate students, aged between 19 and 25, from Universiti Malaysia Sarawak were selected for this study, with 31 (62\%) female and 19 (38\%) male participants. They were divided into two groups, namely, the listening group and the reading group. We altered 14 items in a narrative which included the name of characters, origin of characters, and actions to test the participants' recall of specific items. The original storyline was retained. The items were selected based on their importance to the development of the story and also based on their roles according to Propp's characterisation functions (Tomaszewski \& Binsted, 2007). In the alteration of items, we took care to ensure that none of the altered forms could be found in any sources, online or printed. To the best of our knowledge, the 14 
altered items can only be found in the narrative which we used in this study. The language was also simplified to ensure that language proficiency did not interfere.

Our aims were to find out how much of these items would be retained through listening compared to reading, and if participants with schema about the narrative would retain more items compared to those who did not possess the schema. In this sense, this study resembles the study by Srull (1983) which studied what participants recalled after being fed with manipulated input.

The original narrative in this study was a folktale on how Mount Santubong was formed (see Appendix A). It was chosen as it is quite well-known and it contains several references which makes it uniquely Sarawak. In addition, the folktale was once made into a popular song (see Appendix B) which tells about the two beautiful princesses, Santubong and Sejinjang, who were good friends initially, but then started to fight with each other. In the end, Santubong was cursed into a mountain (Mount Santubong) and Sejinjang into an island (Kera Island). In the original story, the princesses came from Kayangan, a mythical place of origin which can be found in the local folklore. The substitute that we selected, Bunian, is also found in many folktales. The names of places (altered addition: Pantai Puteri) and characters (original name: Putera Mahkota Serapi, altered name: Putera Mahkota Bako) in the narrative would have been familiar to most Sarawakians. Pantai Puteri is a real beach which exists in Kuching, Sarawak. Serapi is the name of another mountain in the Kuching district, whilst Bako is Sarawak's prominent national park.

Data collection for the study took place in three steps. The first step was to distribute pre-selection questionnaire which dealt with the participants' schemata regarding the folktale. Participants were required to assess their own knowledge of the folktale through a Likert Scale ranging from 1 (Never heard of it) to 4 (Very familiar). Those who claimed that they were familiar with the narrative were then required to write a short synopsis of what the story was about. Meanwhile, those who had no prior knowledge of the narrative were required to write their opinion on what they thought the story might be about.

Next, depending on their group, the participants were given an altered version of the narrative text. The listening group consisted of 25 participants and was called the ML group. The reading group contained 25 participants and was called the MR group. ML was required to listen to the recorded version of the narrative, twice. Repetition was done to avoid comprehension issues as the recording was in English. Once the listening exercise ended, the students were asked to write whatever they remembered from the recording. MR was given a written text of the altered narrative to read. After five minutes, they were asked to return the text and write whatever they remembered from what they read. This step of recall protocol was considered as the immediate post-test or post-test 1 .

The third step, known as post-test 2 or the delayed post-test, was conducted two weeks later. Participants from both groups were asked to write whatever they could recall from the narrative which they had either listened to or read two weeks before. In order to avoid language problems, we allowed participants to code-switch in the writings. Nonetheless, as the language proficiency of the participants had been controlled earlier (all participants were of intermediate level), all of them responded in English. 


\section{Results and Discussion}

The first research objective looks at differences in the overall retention of altered items. Interestingly, for all four post-tests in both types of input, the trends of specific item recall were similar, as illustrated in Figure 1.

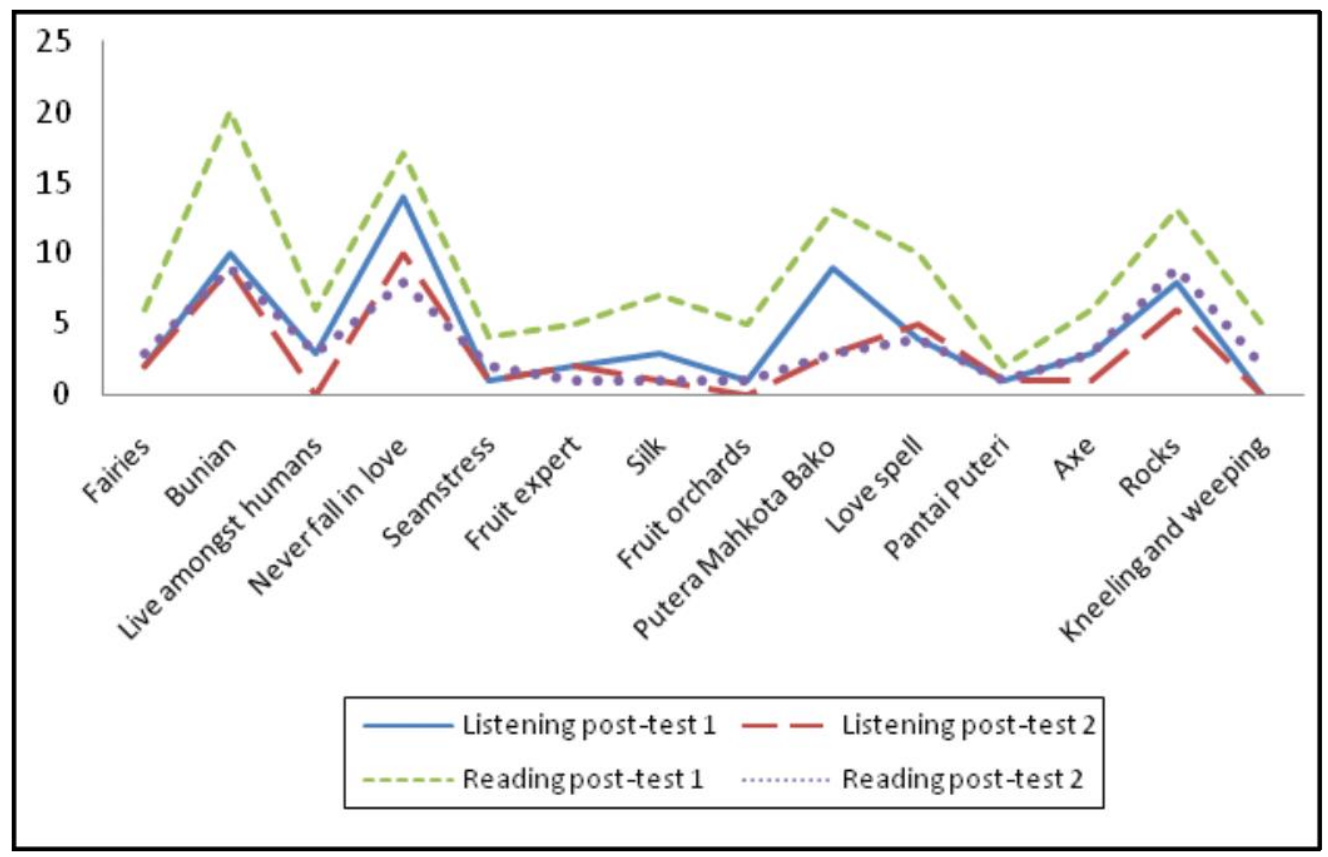

Figure 1. Trends of specific item recall for the immediate and delayed post-tests for listening and reading

It is clear from the line graph that the immediate recall after reading was the highest. Nevertheless, two weeks later, very distinct drops can be seen in the recalled items. On the other hand, immediate recall after listening was lower, but the differences in recall two weeks later did not show a gap as big as the differences between the first and second reading post-tests. Figure 1 shows that after two weeks, despite the earlier difference in the immediate recall test, the levels of specific item retention for both types of input were actually quite similar.

The similarity in the types of recalled items was striking. The four peaks of all post-tests were for Item 2 (Bunian), Item 4 (Never fall in love), Item 9 (Putera Mahkota Bako), and Item 13 (Rocks). It was conjectured that the higher recalls for these altered items was due to the fact that these four items represented important points in the story. According to Propp's feature classifications (Tomaszewski \& Binsted, 2007), Item 2 (Bunian) is Absentation; Item 4 (Never fall in love) is Interdiction; Item 9 (Putera Mahkota Bako) is the Villain, and Item 13 (Rocks) is the Punishment. Even though Malaysian folktales may not fulfil all 31 features as listed by Propp (Martin, 2009), these four features are culturally familiar in most folktales. Item 13 (Rocks) may be recalled more often as stones and rocks are familiar 
occurrences in Malaysian folktales as part of the punishment (see Martin, 2009). Particularly striking is the high peak of recall for Item 2 (Bunian). We believed that this was caused by the local schema concerning the belief in the existence of Orang Bunian (elf-like creatures). As the altered item in our narrative put Bunian as the origin of the princesses, some participants might have associated the place with their local schemata.

To find out whether there are differences in the percentage of retention between the immediate post-test and the delayed post-test, we then converted the number of recall for each item into percentage and compared the numbers. The results for listening are shown in Table 1.

Table 1

Percentage of retention during post-test 1 and post-test 2 for listening input

\begin{tabular}{cccc}
\hline Items & $\begin{array}{c}\text { Post-listening 1 } \\
(\%)\end{array}$ & $\begin{array}{c}\text { Post-listening 2 } \\
(\%)\end{array}$ & Difference \\
\hline 1 & 8 & 8 & 0 \\
2 & 40 & 36 & 4 \\
3 & 12 & 0 & 12 \\
4 & 56 & 40 & 16 \\
5 & 4 & 4 & 0 \\
6 & 8 & 8 & 0 \\
7 & 12 & 4 & 8 \\
8 & 4 & 0 & 4 \\
9 & 36 & 12 & 24 \\
10 & 16 & 20 & -4 \\
11 & 4 & 4 & 0 \\
12 & 12 & 4 & 8 \\
13 & 32 & 24 & 8 \\
14 & 0 & 0 & 0 \\
\hline Total & 244 & 164 & 80 \\
$x / 100 \%$ & 17.43 & 11.71 & 5.71 \\
\hline
\end{tabular}

Table 1 shows that only $17.43 \%$ of items were recalled in the immediate post-test. This dwindled to $11.71 \%$ in the delayed post-test. In the immediate posttest, participants seemed to recall Item 4 (Never fall in love with a human being) the most, followed by Item 2 (Bunian), and Item 9 (Putera Mahkota Bako). None of the participants recalled Items 1 (Fairies), 5 (Seamstress), 6 (Fruit expert), 11 (Pantai Puteri) and 14 (Kneeling down/weeping). The delayed post-test showed a small variation in the recalled items. The first two items were the same (Items 4 and 2), but the third highest recalled item shifted from Item 9 (Putera Mahkota Bako) to Item 10 (Cast a love spell) and Item 13 (Rocks). The illustrated differences can be seen in Figure 2. 


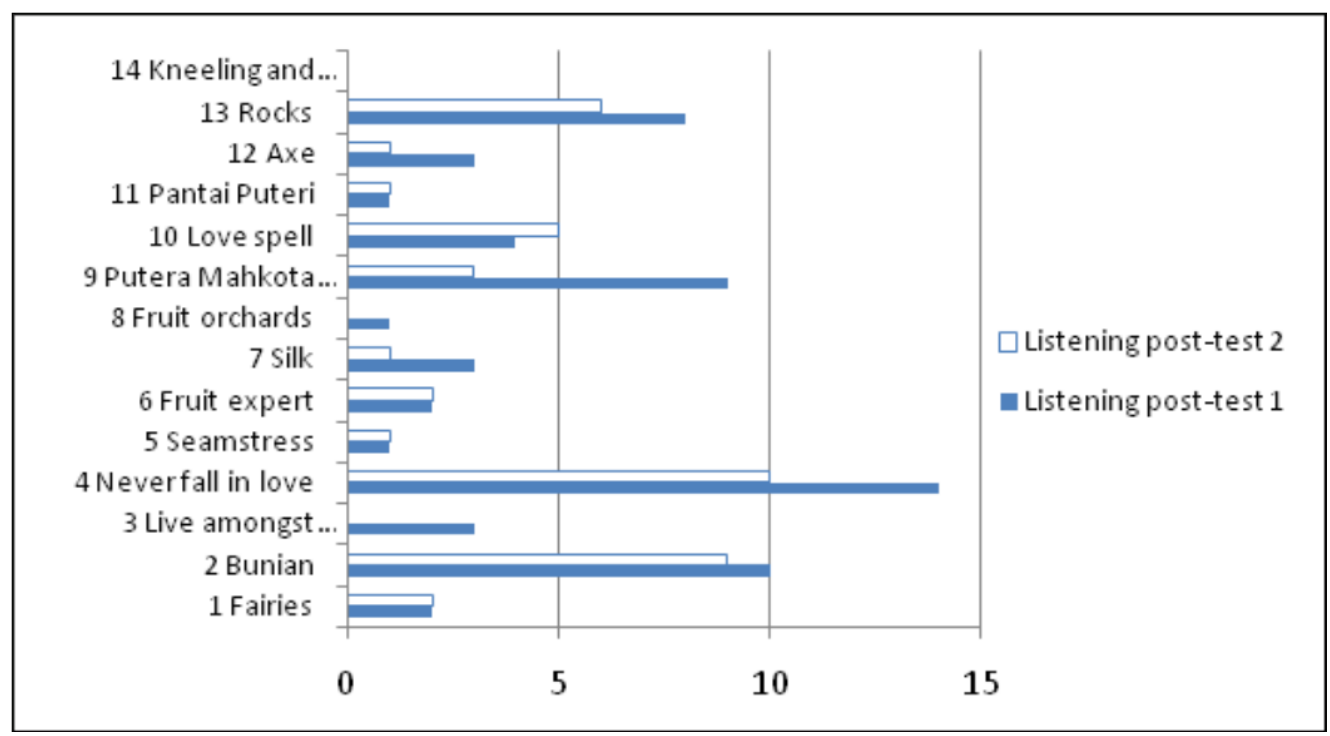

Figure 2. Frequency of specific item recall in the immediate and delayed post-tests for listening input

Item 9 (Putera Mahkota Bako) was found to be the item which deteriorated the most if one took into account the decrease in frequency. Meanwhile, Item 3 (Live amongst human) and 8 (Fruit orchards) were fully lost after two weeks. Worthy of note is the addition of Items 10 and 13 which were not mentioned in the immediate recall, but appeared two weeks later in the recall protocols of two participants. Item 1 (Fairies) and Item 6 (Fruit expert) were equally recalled in both post-tests by the same participants. Surprisingly, one item (Item 10: Love spell) gained more recall in the delayed post-test, although the increase in retention was only by one. This sudden recall of an item which was not remembered in the immediate post-test is intriguing, but as it only involved one participant, it might be idiosyncratic.

The same tabulations were applied for results from the reading post-tests. The results are shown in Table 2.

Table 2

Percentage of retention during post-test 1 and post-test 2 for reading input

\begin{tabular}{cccc}
\hline Items & $\begin{array}{c}\text { Post-listening 1 } \\
(\%)\end{array}$ & $\begin{array}{c}\text { Post-listening 2 } \\
(\%)\end{array}$ & Difference \\
\hline 1 & 24 & 12 & 12 \\
2 & 80 & 36 & 44 \\
3 & 24 & 12 & 12 \\
4 & 68 & 32 & 36 \\
5 & 16 & 8 & 8 \\
6 & 20 & 4 & 16 \\
7 & 28 & 4 & 24 \\
8 & 20 & 4 & 16 \\
9 & 52 & 12 & 40 \\
\hline
\end{tabular}




\begin{tabular}{cccc}
\hline 10 & 40 & 16 & 24 \\
11 & 8 & 4 & 4 \\
12 & 24 & 12 & 12 \\
13 & 52 & 36 & 16 \\
14 & 20 & 8 & 12 \\
\hline Total & 476 & 200 & 276 \\
$\mathrm{x} / 100 \%$ & 34.00 & 14.29 & 19.71 \\
\hline
\end{tabular}

A higher retention percentage was shown for reading, as $34.00 \%$ of items were recalled during the immediate post-test. As shown in Table 2, the items which had the highest recall during the immediate post-test were Item 2 (Bunian), followed by Item 4 (Never fall in love), and Items 13 (Rocks) and 9 (Putera Mahkota $B a k o)$. The one distinct difference compared with the immediate listening post-test was the appearance of Item 13 (Rocks) on the list. The delayed post-test showed a sharp drop of recall to $14.29 \%$, which was more than half of the original percentage of recall. Items with the highest recall stayed similar, with the exception of Item 10 (Love spell) which was not one of the items with the highest recall during the immediate post-test.

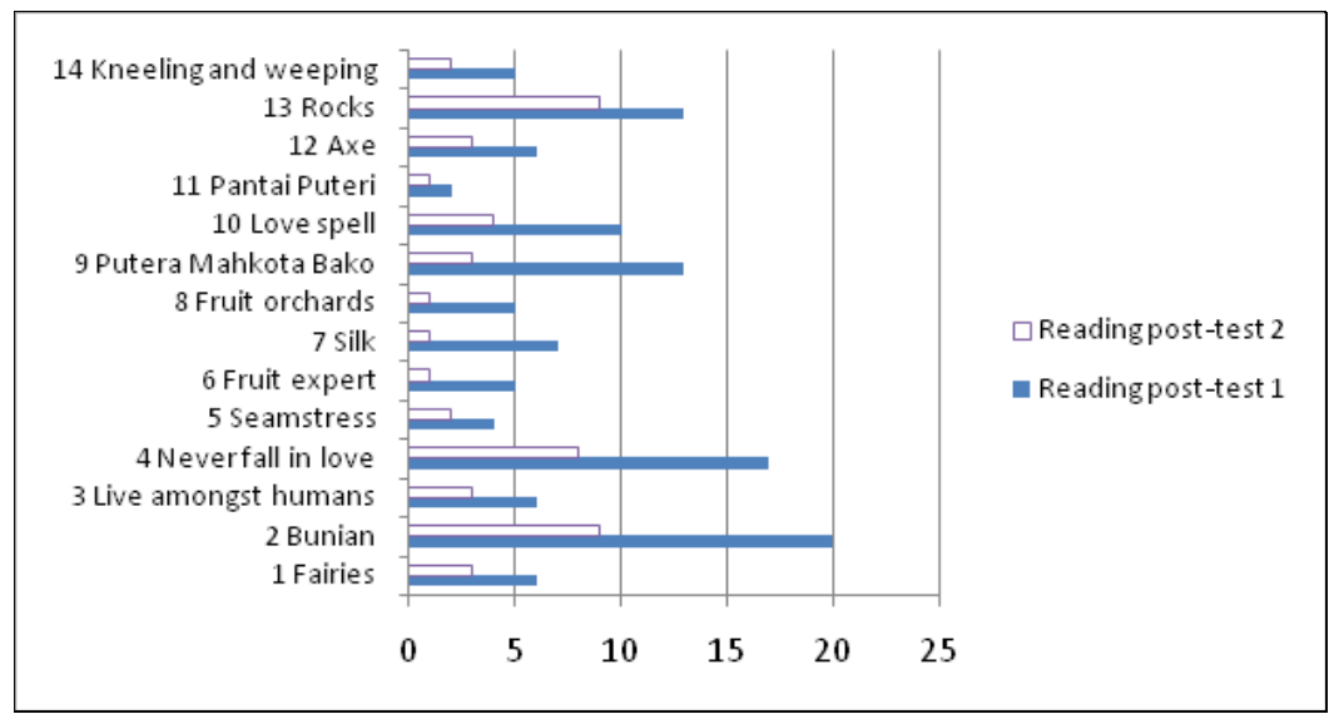

Figure 3. Frequency of specific item recall in the immediate and delayed post-tests for reading input

Input through reading showed the highest recall of items; however, it also showed the highest percentage of deterioration (Figure 3). Item 7 (Silk) deteriorated by $85.7 \%$, which was the highest percentage of deterioration, followed by Item 8 (Fruit orchards) at $80.0 \%$ and Item 9 (Putera Mahkota Bako) at $76.9 \%$. The overall decline in item recall in the delayed post-test for reading was more significant than the overall decline in item recall for listening. This finding was similar to Vidal's (2011) findings on the retention of reading and listening to academic texts. Vidal found that listening left "more durable traces than reading" for the more proficient 
learners in her study, which led to better retention of words for listeners compared to readers (p. 244). This is an interesting insight. Since the pattern in our study mimicked Vidal's observation, it might indicate that the same pattern applies for both academic and narrative texts.

Our third research question deals with the differences between participants with prior knowledge and those without prior knowledge of the narrative. SchmidtReinhart (1994) and Srull (1983) found that participants with prior knowledge had better scores when tested compared to participants without the knowledge. On the other hand, research like Vidal's (2011) demonstrated that listeners scored better in post-tests than readers when it came to retention. To determine which trend would appear in this study, we classified participants who showed that they possessed adequate prior knowledge of the folklore by selecting those who can write a synopsis with an accurate or almost accurate (e.g., one or two minor errors such as the spelling of names) storyline and compared their results with those who did not possess the schemata for the narrative. Overall findings revealed that participants with schemata were able to recall more items, although some items were new and inaccurate. This finding therefore supported previous findings (e.g., Srull, 1983) which showed that schema assisted in retention. However, the finding that listening input resulted in better retention still held true. The best result for retention was achieved when the two constructs (input through listening and presence of schema) were combined, as summed up in Table 3.

Table 3

Differences in the retention and deterioration of items (\%) between participants with schema and with little or no schema for reading and listening input

\begin{tabular}{|cccc|}
\hline Group & $\begin{array}{c}\text { Recall of items for post- } \\
\text { test 1 (\%) }\end{array}$ & $\begin{array}{c}\text { Recall of items for } \\
\text { post-test 2 (\%) }\end{array}$ & $\begin{array}{c}\text { Deterioration in two } \\
\text { weeks (\%) }\end{array}$ \\
\hline ML & With schema & 23.63 & 18.13 \\
& With little or no & 10.71 & 4.76 \\
schema & & 15.71 \\
MR & With schema & 31.43 & 13.93 \\
& With little or no & 34.64 & \\
\hline
\end{tabular}

The ML group had a balanced number of participants with 13 who were familiar with the folklore and 12 who were not. The immediate post-test corresponded to Schmidt-Reinhart's (1994) and Chiang and Dunkel's (1992) findings as those with prior knowledge were able to recall $23.63 \%$ of the items, far higher than those who were not familiar with the folktale. Participants with little or no schemata were only able to recall $10.71 \%$ of the items. The delayed post-test saw a decline in retention of the items. Interestingly, the levels of deterioration for both participants with and without schema were almost similar at 5.49\% and 5.95\% respectively. Nonetheless, participants with schema still held the higher retention percentage of $18.13 \%$ compared to $4.67 \%$ from these without schema. 
The reading post-tests from the MR group, however, showed a different outcome. Only five participants were deemed as familiar with the folktale. The remaining 20 participants did not possess the schemata. Participants with schema were able to recall $31.43 \%$ of the items, whilst participants with little or no schema recalled a slightly higher percentage (34.64\%) in the immediate post-test. In the delayed post-test, participants with schema could only recall $15.71 \%$ of the items, whilst those with little or no schema recalled $13.93 \%$. The percentage of deterioration of those with schema was $15.71 \%$, a decline of exactly half. Meanwhile, the percentage of deterioration of those without schema was $20.71 \%$, a higher percentage compared to the listening post-tests result. As a matter of fact, within two weeks, participants who read the altered folktale had forgotten approximately three to four times the percentage of items recalled by those who listened to the folktale, even though it can be argued that those with prior knowledge about the folktale still had better recollection of items. This is in accordance with Pritchard's (1990) findings that participants who were more familiar with a text recalled more idea units when they read the text compared to those who had no prior knowledge.

From these findings, we concluded that the listening post-tests showed a higher retention level in the immediate post-test for those with schema than those with little or no schema, but with almost the same level of deterioration for both. The opposite occurred in the reading post-tests as participants with little or no schema actually recalled more items, but deteriorated at a much higher level compared to those with prior knowledge.

\section{Conclusion}

The results from this study showed that the overall retention of altered items followed a similar pattern. From this, four items were recalled the most, namely, Item 2 (Bunian), Item 4 (Never fall in love), Item 9 (Putera Mahkota Bako), and Item 13 (Rocks). We argue that the recall for these four items was higher in all four posttests for both types of input as they formed the usual backbone of Malaysian folktales and also because they are part of narrative folktale/fairytale features as demonstrated in Propp's characterisations. This study provided evidence in accordance with previous research on schema, which showed that participants with schema recalled more information. It also provided evidence in accordance with listening and reading input, which showed that input by listening resulted in better retention. Nevertheless, the combination of listening and presence of schema produced the best retention and the lowest deterioration.

\section{References}

Baldwin, R. S., Peleg-Bruckner, Z., \& McClintock, A. H. (1985). Effects of topic interest and prior knowledge on reading comprehension. Reading Research Quarterly, 20(4), 497-504. 
Brewer, W. F., \& Nakamura, G. V. (1984). The nature and functions of schemas. In S. W. Robert \& K. S. Thomas (Eds.), Handbook of social cognition (pp. 119-160). Hillsdale, NJ: Erlbaum.

Carrell, P. L. (1983, March). Some issues in studying the role of schemata, or background knowledge, in second language acquisition. Paper presented at the TESOL Convention, Toronto, Canada.

Carrell, P. L., \& Eisterhold, J. C. (1983). Schema theory and ESL reading pedagogy. TESOL Quarterly, 17(4), 553-573.

Chiang, C. S., \& Dunkel, P. (1992). The effect of speech modification, prior knowledge, and listening proficiency on EFL lecture learning. TESOL Quarterly, 26(2), 345-374.

Ellermeyer, D. (1993). Improving listening comprehension through a whole-schema approach. Early Child Development and Care, 93(1), 101-110.

Kramsch, C. (1993). Context and culture. Oxford, UK: Oxford University Press.

Long, D. R. (1989). Second language listening comprehension: A schema-theoretic perspective. The Modern Language Journal, 73(1), 32-40.

Markham, P., \& Latham, M. (1987). The influence of religion-specific background knowledge on the listening comprehension of adult second-language students. Language Learning, 37(2), 157-170.

Martin, J. S. (2009). Analysis on structural pattern of plotline and myths in Malaysian folktales. Unpublished undergraduate thesis. Universiti Malaysia Sarawak, Malaysia.

McVee, M. B., Dunsmore, K., \& Gavelek, J. R. (2005). Schema theory revisited. Review of Educational Research, 75(4), 531-566.

Pritchard, R. (1990). The effects of cultural schemata on reading processes strategies. Reading Research Quarterly, 25(4), 273-295.

Reynolds, R. E., Taylor, M. A., Steffenson, M. S., Shirey, L. L., \& Anderson, R. C. (1982). Cultural schemata and reading comprehension. Reading Research Quarterly, 17(3), 353-366.

Sadighi, F., \& Zare, S. (2006). Is listening comprehension influenced by background knowledge of the learners? A case study of Iranian EFL learners. The Linguistics Journal, 1(3), 110-126.

Schmidt-Reinhart, B. C. (1994). The effects of topic familiarity on second language listening comprehension. The Modern Language Journal, 78(2), 179-189.

Shapiro, A. M. (2004). How including prior knowledge as a subject variable may change outcomes of learning research. American Educational Research Journal, 41(1), 159-189.

Srull, T. K. (1983). The role of prior knowledge in the acquisition, retention, and use of new information. Advances in Consumer Research, 10, 572-576.

Tomaszewski, Z., \& Binsted, K. (2007). The limitations of a Propp-based approach to interactive drama. In B. S. Magerko \& M. A. Riedl (Eds.), Intelligent narrative technologies: Papers from AAAI Fall Symposium (pp. 166-172). Menlo Park, CA: AAAI Press.

Vidal, K. (2011). A comparison of the effects of reading and listening on incidental vocabulary acquisition. Language Learning, 61(1), 219-258. 


\section{Appendix A \\ Original version of the folktale}

There is a famous legend behind Mount Santubong in Sarawak that recounts of two beautiful mythical sisters. Princess Santubong and Princess Sejinjang were both from the magnificent and idyllic mythical kingdom called Kayangan. Both were sent to earth to restore peace between the neighbouring villages of Pasir Kuning and PasirPutih, with a strict condition that they must never quarrel with each other, as decreed by the mighty King of Kayangan.

Princess Santubong, an experienced weaver, was to rule over PasirKuning while Princess Sejinjang, a skilled rice thresher, was to rule over PasirPutih. Princess Santubong's intricately woven fabrics were an instant success while Princess Sejinjang's paddy fields were greatly thriving. Both villages soon prospered greatly. The beauty and talent of both princesses made them much sought after by suitors from all over the place. None won their heart until they met Putera Mahkota Serapi (Crown Prince Serapi) from Matang. The crown prince fell in love with both of them, but they refused to be joint wives.

Because of him, they had an awful quarrel and exchanged blows. Sejinjang swung her thresher and hit Santubong's cheek which made her fell flat on her back. Santubong threw her weaver at Sejinjang, hitting her directly at her head. The great King of Kayangan was so angry that he cursed both of them into mountains, putting an end to the fight.

It is said that the Mount Santubong resembles a woman lying on her back. The deep crevice at the peak is where the princess got hit on the cheek.

The legend was then told in a song called "Puteri Santubong" sung in local Malay dialect. It is often played by local radio stations.

Taken from http://malaysiastories.blogspot.com/2009/05/legend-of-puterisantubong.html 


\section{Altered version of the folktale}

There is a famous legend behind Mount Santubong in Sarawak that tells of two beautiful mythical sisters. Princess Santubong and Princess Sejinjang were both fairies from the land of Bunian. They were sent to earth to learn to live amongst humans but with one condition, they must never fall in love with a human being.

Princess Santubong, an experienced seamstress, was to rule over PasirKuning while Princess Sejinjang, a fruit expert, was to rule over PasirPutih. Princess Santubong'ssilk costumes were an instant success while Princess Sejinjang's fruit orchards were greatly flourishing. Both villages soon became very well-known.

The beauty and talent of both princesses made them much sought after by suitors from all over the place. None won their heart until they met Putera Mahkota Bako. The crown prince cast a love spell, making both of them fall in love with him.

Because of him, they had an awful quarrel at Pantai Puteri and started to hit one another. Sejinjang swung her axe and hit Santubong's cheek which made her fell flat on her back. Santubong threw her own axe at Sejinjang, hitting her directly at her head. The great King of Bunian was so angry that he cursed both of them into rocks, putting an end to the fight.

It is said that Mount Santubong resembles women kneeling down, weeping. The legend was then told by the people to each other to remember the two princesses and their unhappy ending. 


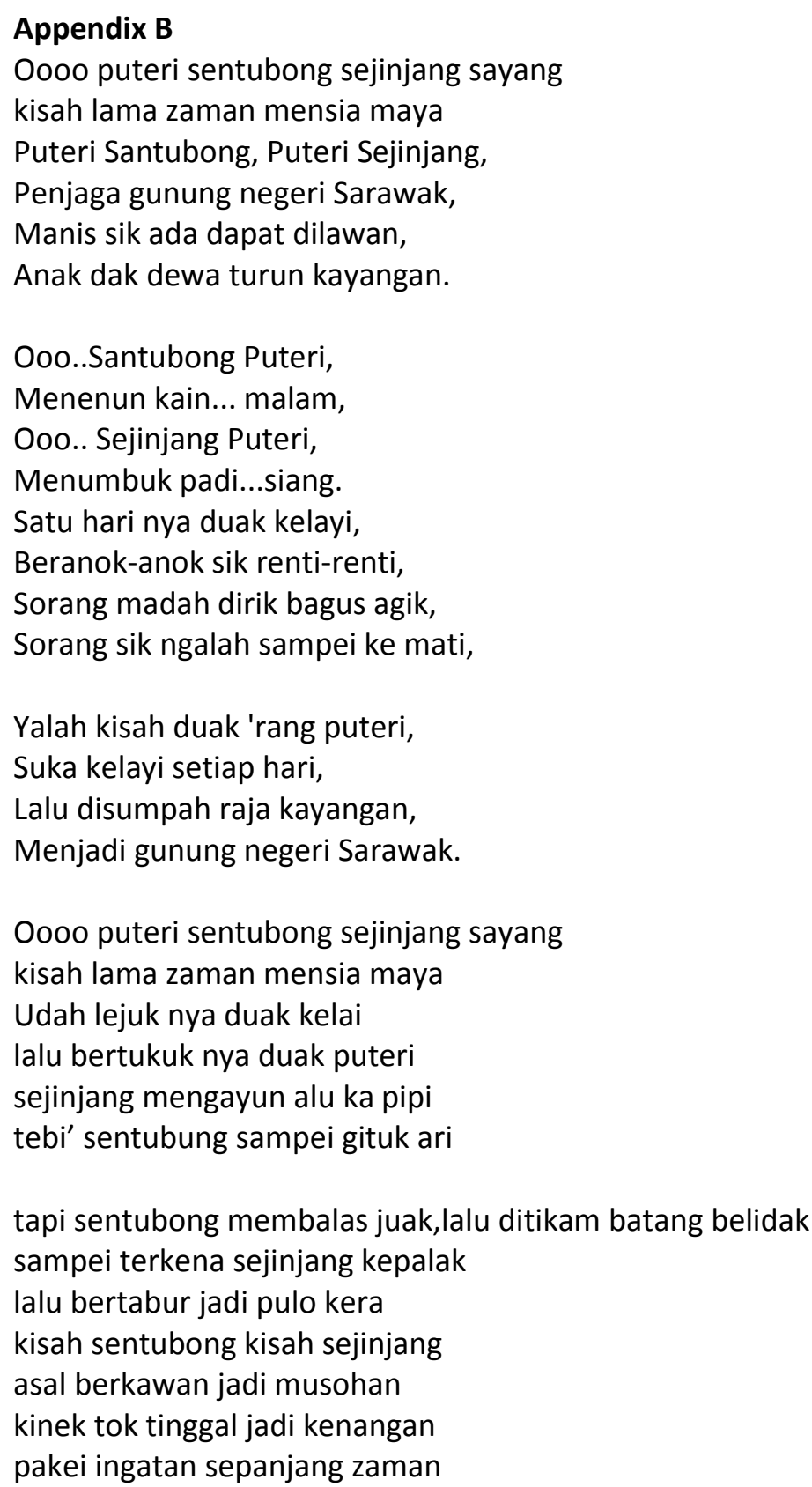

